\title{
The spatial stability of alcohol outlets and crime in post-disaster Christchurch,
}

\author{
New Zealand \\ Gregory D. Breetzke ${ }^{1}$ and Martin A. Andresen ${ }^{2}$ \\ ${ }^{1}$ Department of Geography, Geoinformatics and Meteorology, University of Pretoria, Pretoria, South Africa; \\ ${ }^{2}$ School of Criminology and Institute for Canadian Urban Research Studies, Simon Fraser University, Burnaby, \\ Canada
}

\begin{abstract}
The devastating Canterbury Earthquakes of 2010 and 2011 left an indelible mark on the city of Christchurch. The social and economic upheaval that immediately followed the Earthquakes has, in time, been replaced with a period of rebuild and transformation. In this study we investigate the effects that the Canterbury Earthquakes had on two important and inter-related phenomena in the city: alcohol availability and crime. More specifically, we investigate how alcohol outlets and crime across six different categories changed in magnitude and spatial distribution pre- (end-2009) and post- (end-2014) earthquake. We do this using a variety of geospatial techniques including a relatively new method: the spatial point pattern test which allows for the identification of changes in spatial patterns at the local level. Results indicate that both alcohol outlets and crime have decreased in magnitude since the Canterbury Earthquakes. Using the spatial point pattern test we found statistically significant differences in spatial point patterns for both alcohol outlets and all crime types pre- to post-earthquake. The similarity in the differences of the spatial distributions of alcohol outlets and crime provides a first empirical clue of their potential association in the city postearthquake.
\end{abstract}

Keywords: alcohol outlets; crime; earthquake; spatial point pattern test; New Zealand 


\section{Introduction}

Considerable evidence suggests the effects of a natural disaster are linked to increased alcohol consumption (Schroeder \& Polusny 2004; Cepeda et al. 2010) and alcohol-related harm (Rohrbach et al. 2009; Cerdá et al. 2011). The causal pathways underlying these relationships are generally thought to be related to the psychosocial stressors experienced by residents following a natural disaster. There is also evidence that natural disasters greatly impact the magnitude and nature of crime. Results across this broad swathe of literature are mixed with some studies finding an increase in crime post-disaster (Gray \& Wilson 1984; Zhou 1997; LeBeau 2002; Leitner \& Helbich 2011), while others indicate an associated decrease (see Watanabe \& Tamura 1995; Cromwell et al. 1995; Barsky et al. 2006; Zahran et al. 2009).

Whilst much prior research has analyzed the associations between natural disasters and their effect on alcohol consumption and crime two important factors have been consistently neglected. First, how does the location of alcohol outlets change in the aftermath of a natural disaster? And second, what impact does a natural disaster have on the spatial distribution of crime? In this short, descriptive study we examine the impact that the Canterbury Earthquakes had on the number and spatial patterning of both alcohol outlets and crime in Christchurch, New Zealand. The Canterbury Earthquakes refer to the two main earthquake events that struck the Canterbury region of the South Island of New Zealand between September 2010 and February 2011. The first earthquake of the sequence, a moment magnitude $\left(M_{w}\right) 7.1$ earthquake struck on the $4^{\text {th }}$ September 2010 (Darfield Earthquake), and a moment magnitude $M_{w} 6.2$ earthquake struck on the $22^{\text {nd }}$ February 2011 (Christchurch Earthquake). In this study we examine the impact that these earthquakes have had on the magnitude and distribution of alcohol outlets and crime in the city. Importantly, in this study we are not interested in examining the causes or consequences of the changing magnitude and 
spatial patterning of alcohol outlets and crime in Christchurch, if any are observed, but rather focus here on examining whether any changes occurred and where. The rest of the paper proceeds as follows. First, we provide a brief overview of past research examining the impact of natural disasters on alcohol availability, and crime distributions in affected regions before we outline our data and methods, and provide our results. Our discussion concludes.

\section{Related research}

Alcohol availability

Research has shown how the spatial distribution of alcohol outlets is important in understanding the relationship between neighborhood contexts and excessive alcohol consumption (see Cameron et al. 2012; Day et al. 2012; Ayuka et al. 2014). Knowing how the spatial distribution of alcohol outlets change in the aftermath of a natural disaster seems especially important because natural disasters greatly impact the affected population and have been shown to lead not only to a change in attitudes to life (see Burke et al. 1982; MearidyBell 2013) and mental health of residents (Ursano et al. 2009), but also to an increase in risktaking behaviours (Cameron \& Shah 2015). Despite this, and rather surprisingly, we are unaware of any previous study that has examined how the spatial distribution of alcohol outlets change in the aftermath of a natural disaster. Most prior studies examining the spatial change in alcohol outlet density on alcohol related harm have done so in the context of changing alcohol legislation and/or regulation, particularly in the United States. Research has found that an increase in alcohol outlet density generally results in a concomitant rise in a range of adverse outcomes in affected neighbourhoods including crime (see Conrow et al. 2015), violence (Gruenewald \& Remer 2006; Livingston 2008), and attempted and completed suicides (Johnson et al. 2009). Conversely, a reduction in alcohol availability in neighbourhoods has been found to be associated with a significant reduction in exposure to 
violent crime (Zhang et al. 2015), a reduction in gonococcal infection rates (Cohen et al. 2006) in affected neighbourhoods, and an increase in voting rates (Scribner et al. 2007). In this research, we investigate how alcohol outlets change in the aftermath of a natural disaster despite substantial evidence that shows the likely consequences of a change (increase or decrease) in outlet density in neighbourhoods.

\section{Crime}

Many studies have investigated the impact of a natural disaster on the magnitude of crime. Results of this literature covering numerous geographic locales are mixed with some studies reporting an increase in crime post-disaster while other report a decrease. In terms of the former, Zhou (1997) found an increase in property crime in the year following the Tangshan Earthquake of 1976 while LeBeau (2002) noted an increase in the number of burglaries and domestic disputes after Hurricane Hugo in Charlotte, North Carolina in 1989. In the aftermath of the Mount Saint Helens ash fall event, Adams and Adams (1984) identified a 46 percent increase in domestic violence offences in Othello, Washington. More recently, Leitner and Helbich (2011) noted a tripling of burglary offences in Houston, Texas following Hurricane Rita while Walker et al. (2012) and Walker et al. (2014) found an increase in burglary and larceny-theft following Hurricane Wilma (in Miami) and Hurricane Ivan (in Mobile, Alabama) respectively. Finally, Zahran et al. (2009) found a positive relationship between domestic violence and the frequency of hurricanes in Florida between 1992 and 2005, a finding supported by a number of single incidence studies (see Fothergill 1996; Morrow 1997).

In terms of the latter, Barsky et al. (2006) found a decrease in burglary and theft offences in New Orleans following Hurricane Katrina while Leitner et al. (2011) also observed falling property crime rates across eleven counties of Louisiana after the same event. Other studies 
noting a decrease or relative stability in crime post-disaster include Watanabe and Tamura (1995), Cromwell et al. (1995), Lee (2010), and Leitner and Helbich (2011). Reasons for the conflicting results are myriad and are seen to be related to the underlying socio-economic conditions of each geographic locale (Harper \& Frailing 2012), inter- and intra-migration patterns (Varano et al. 2010), as well as the severity of the disaster itself (Prelog 2016).

Interestingly, studies examining the changing spatial patterning of crime in the aftermath of a natural disaster have been less forthcoming. Natural disasters cause significant upheaval particularly to the built environment of affected cities and it seems reasonable to assume that spatial crime patterns will likely alter as a consequence. Research using spatial statistics to understand the behavior of criminal activity after a disaster include Leitner and Helbich (2011) who noted an increase in hotspots of burglary following the week of Hurricane Rita's landfall - these hotspots were also found to be in locations away from their 'usual' locations while increases in the spatial clustering of burglary and larceny-theft in non-typical locations were also found following Hurricane Ivan (Walker et al. 2012) and Hurricane Wilma (Walker et al. 2014), respectively. We are unaware of any previous study that has examined how an earthquake influences the spatial patterning of crime in affected cities.

\section{The current study}

This study examines the impact that the Canterbury Earthquakes have had on the number and spatial patterning of alcohol outlets and crime in Christchurch. We extend the current literature on this topic in a number of ways. First, we examine how both alcohol outlets and crime changes and spatially diffuses in a city post-disaster. In terms of crime, we examine how crime as a whole as well as across six different categories (assault, robbery, burglary, theft, social incivilities, motor vehicle theft) change in magnitude and distribution following the Canterbury Earthquakes. Second, we use a relatively new methodological technique - the 
spatial point pattern test (see Andresen 2009) - to examine and identify significant changes in these spatial distributions pre- and post-quake. This is the first use of this geospatial technique to examine the impact of a natural disaster on changing crime patterns. And third, we explore the effect of a natural disaster on crime in a new context and geographic locale. Most prior research has concentrated on the effects of hurricanes and tsunamis on crime rates while previous examinations of this relationship has been almost exclusively done in the United States and Asia and/or in high crime locales.

\section{Data and methods}

\section{Alcohol outlet and crime data}

An alcohol outlet geodatabase was built especially for this study by contacting all liquor license holders recorded by Alcohol Regulatory and Licensing Authority (ARLA) as having operating alcohol outlets from 2009 to 2014. The ARLA has statutory authority to collect licensing information for all alcohol outlets in the country. The data obtained from ARLA was validated in 2015 using a team of ten computer-assisted telephone interviewers. These interviewers used Voice Over Internet Protocol (VOIP) phones to call all liquor license holders during the period under investigation (pre- and post-earthquake Christchurch). Information was obtained from license holders pertaining to the type of license (on- or offsite), opening and closing (either permanent or temporary) dates of their alcohol outlet/s as a result of the Canterbury Earthquakes as well as more general open ended information regarding the effects the earthquakes had on their alcohol trading businesses. Whilst the reliability and validity of liquor license information obtained from ARLA can be brought into question in a post-disaster setting, the statutory authority is the official source of liquor licensing information in the country. Moreover, the dataset is official and spatially replete. The operating address of each outlet type both pre- and post-earthquake was geocoded and 
located in the 119 census areal units (CAUs) in the city for both time periods: pre-earthquake (December 2009) and post-earthquake (December 2014). A CAU is the second smallest unit of dissemination of census data in New Zealand, with each CAU representing approximately 2,800 people - this is closest in size to the census tract in a North American context.

Crime data for this study were obtained from the New Zealand Police. Reported offences within Christchurch from $1^{\text {st }}$ January 2009 to $31^{\text {st }}$ December 2014 (six years) were obtained. Each offence contained a location (easting, northing), an estimated time of the offence as well as a description and classification. The six-year study period was broken down into a preearthquake period ( $1^{\text {st }}$ January $2009-31^{\text {st }}$ December 2009$)$ and a post-earthquake period $\left(1^{\text {st }}\right.$ January $2014-31^{\text {st }}$ December 2014). The four-year interim period was excluded in the analysis because this period covered the two major earthquake events in the sequence, separated by five months (i.e., September 2010 and February 2011) as well as a significant period of rebuilding. A total of 37,584 offences were reported to the Police across these two periods (pre-earthquake $=20,134$; post-earthquake $=17,450$ ) in the six crime categories examined. Each crime incident was geocoded and, subsequently, located within one of the 119 CAUs in the city.

\section{Spatial analyses: spatial point pattern test and bivariate Moran's I}

The fundamental form of analyzing spatial point patterns is to compare the spatial distribution of a phenomenon with the distributions of complete spatial randomness and uniformity, potentially identifying various degrees of spatial clustering. Most of these tests are global in nature, such that one statistic is generated for the entire study area. Moreover, when one considers that human activities and/or human conditions tend to be clustered in space (Gatrell et al. 1996), knowing that a particular phenomenon is clustered is of limited value. For example, when comparing the spatial distributions of two phenomena using a 
global statistic, each phenomenon may have the same degree of clustering in entirely different places within the study space or different degrees of clustering in the same general area within the study space. Local spatial statistics allow for the identification of where clustering occurs using point-based methods (average nearest neighbor, for example) as well as area-based methods (Anselin 1995; Getis and Ord 1992). However, if the change in a spatial distribution is of interest, a different statistical method is necessary.

In order to identify any changes in the spatial patterns of the presence of alcohol outlets as well as changes in the patterns of crime, a statistical methodology that allows for the identification of changes in spatial patterns, regardless of their formal distribution, that can be identified and visualized at the local level was necessary. Andresen (2009) developed a spatial point pattern test that allows for the identification of similarity between two spatial point patterns. In the current context, this similarity would be between alcohol outlets and, subsequently, crime at different points in time: the spatial pattern of alcohol outlets before and after the earthquakes in Christchurch, the spatial pattern of crime (separated by crime types, discussed above) before and after the earthquakes in Christchurch, and then comparing (visually and statistically) the changes in the spatial pattern of alcohol outlets to the changes in the spatial patterns of crime.

The utility of such an approach can be seen through inspection of Figure 1, representing a large scale view of alcohol outlets (2009 and 2014) the central business district of Christchurch. There is an identifiable cluster of alcohol outlets in 2009 that is not as apparent in 2014. Inspection of the 2014 data does show a density of alcohol outlets compared to outlying areas, but it is not as evident as in 2009. However, is this simply due to a decrease in the number of alcohol outlets because of the earthquake, or does it truly represent a change in the spatial point pattern of alcohol outlets? The spatial point pattern 
test, described below, allows for the identification of statistically significant changes in two (or more) spatial point patterns such as these at the local level.

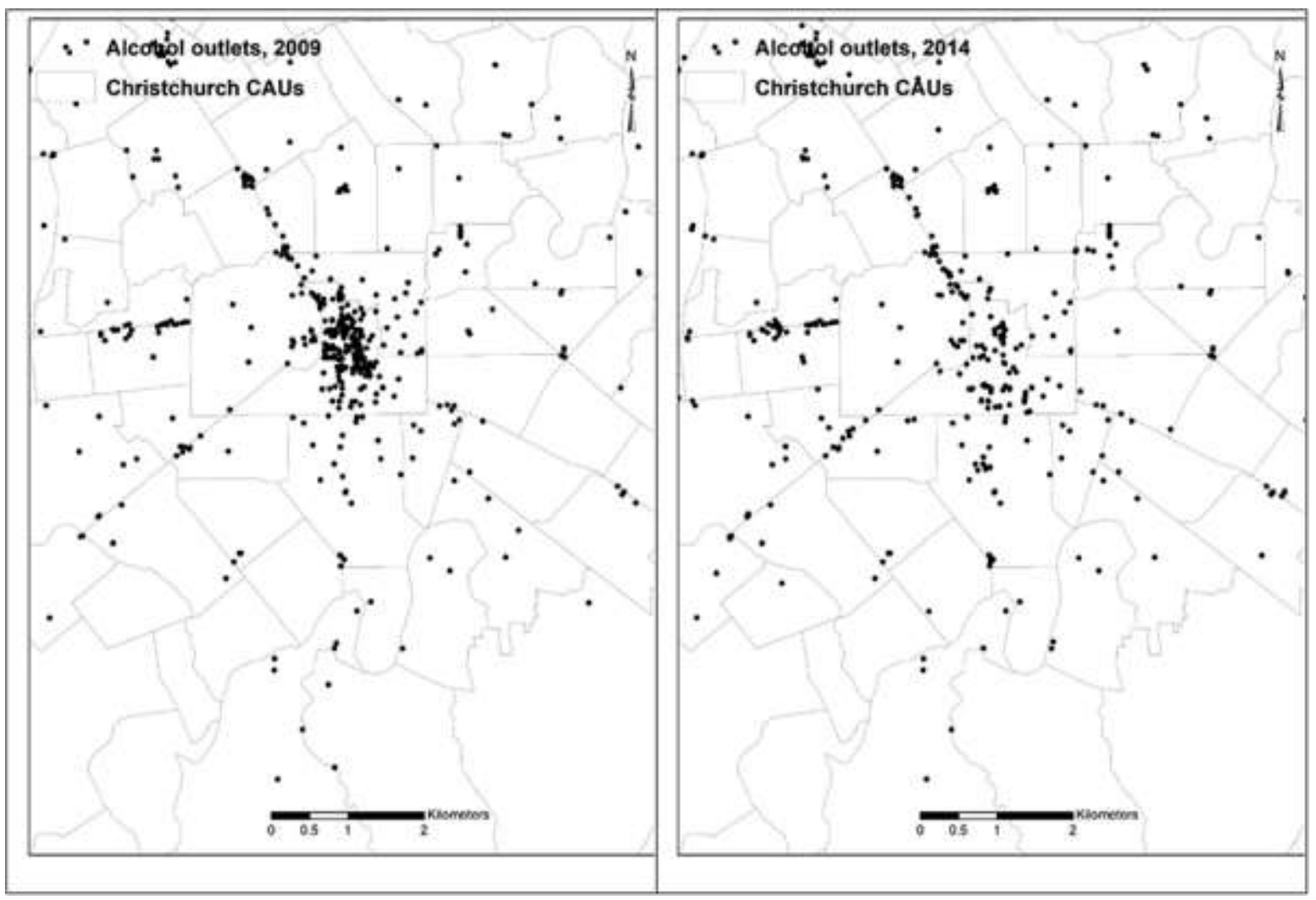

Figure 1. Alcohol outlets, 2009 and 2014.

This spatial point pattern test has been used in a number of contexts including, but not limited to: changing patterns of international trade (Andresen 2010), the spatial similarity of crime patterns for different crime types (Andresen \& Linning 2012), changing spatial patterns of crime across the seasons (Andresen \& Malleson 2013a; Linning 2015), how the modifiable areal unit problem impacts spatial patterns (Andresen \& Malleson 2013b), the changing spatial patterns of crime resulting from police foot patrol (Andresen \& Malleson 2014), and comparing the spatial similarity of actual police data with open source crime data that has undergone a process of adding geographic uncertainty to maintain privacy (Tompson et al. 2015). Needless to say, though most of the applications are related to spatial crime patterns, this spatial point pattern test has been applied in a number of different contexts. 
In order to implement the spatial point pattern test, there are five steps:

1. Nominate a base dataset and count, for each CAU, the number of points that fall within it. The base data set in the current analyses will always be the pre-earthquake year, 2009, for each spatial pattern of interest.

2. From the test dataset (all 2014 data sets), randomly sample 85 percent of the points, with replacement. As with the previous step, count the number of points within each CAU using the sample. This is effectively a bootstrap created by sampling from the test dataset; the percentages are used in order to be able to compare the spatial patterns of phenomena that have different volumes of events such as the changes in the numbers of alcohol outlets and the volumes of crime. An 85 percent sample is based on the minimum acceptable hit rate to maintain spatial patterns, determined by Ratcliffe (2004). Maintaining the spatial pattern of the complete data set is important so we used this as a benchmark for sampling. An 85 percent sample was for the purposes of generating as much variability as possible while maintaining the original spatial pattern. Also note that "replacement" in this context refers to subsequent samples; any one point may only be sampled once per iteration in this procedure to mimic Ratcliffe (2004).

3. Repeat (2) a number of times (200 is the default).

4. For each CAU in the test data set, calculate the percentage of points that have occurred in the CAU. Use these percentages to generate a 95 percent nonparametric confidence interval by removing the top and bottom 2.5 percent of all counts ( 5 from the top and 5 from the bottom in this case). The minimum and maximum of the remaining percentages represent the confidence interval. It should be noted that the effect of the sampling procedure will be to reduce the number of observations in the test dataset but, by using percentages rather than the absolute counts, comparisons 
between data sets can be made even if the total number of observations are different, as stated above.

5. Calculate the percentage of points within each CAU for the base dataset and compare this to the confidence interval generated from the test dataset. If the base percentage falls within the confidence interval then the two datasets exhibit a similar proportion of points in the given area. Otherwise they are significantly different. This comparison for each CAU creates a new categorical variable, $s_{i}$. This new variable takes on the values of 0 (no significant change), 1 (test > base: $2014>2009$ ), and -1 (test < base: 2014 2009); it is important to note that these values are categorical and only used for mapping purposes.

Further details of the test are available in Andresen (2016). ${ }^{1}$

From all this output, there are both global and local results that can be calculated and visualized. The global statistic is calculated as the percentage of CAUs that have been deemed similar in the process described above. This global similarity index, $S$, ranges from 0 , no similarity, to 1 , perfect similarity, and is calculated as follows:

$$
S=\frac{\sum_{i=1}^{n} s_{i}}{n}
$$

Where the absolute value of $s_{i}$ is equal to 1 if the process above identifies the spatial patterns in CAU $i$ as similar and 0 otherwise, and $n$ is the number of CAUs. This calculation transforms the local categorical statistic, $s_{i}$, into a continuous global index that ranges from zero to unity. In the literature, cited above, a value of $S=0.8$ has been deemed as indicating spatial similarity, though this value should be considered a guide, not an absolute. The output from this spatial point pattern test can also be mapped. Because each CAU has its own $s_{i}$ value, these values can be mapped in order to identify where spatial patterns are similar or

\footnotetext{
${ }^{1}$ We use the graphical user interface provided by Nick Malleson to undertake the spatial point pattern test: https://github.com/nickmalleson/spatialtest.
} 
changing across time. Such visualizations can then be used to identify if the changes in one spatial pattern are occurring in the same places as another spatial pattern: changes in the spatial pattern of alcohol outlets and changes in the spatial pattern of crime, in the current context.

Though comparing the visualizations of the spatial point pattern test outputs may be instructive, it is important to test, statistically, if these patterns are changing in similar ways, as hypothesized above. We undertake two analyses in order to investigate these changes, one spatial and one non-spatial. The spatial method we employ is the bivariate Moran's I. The bivariate Moran's I tests for the presence of spatial correlation between two interval variables rather than with spatially lagged values of the same variable (spatial autocorrelation). As such, if the bivariate Moran's $I$ statistic is positive and statistically significant this will indicate that the changes in the spatial patterns of alcohol outlets and crime are similar. However, we interpret this statistic with caution because the output from the spatial point pattern test is categorical: numbers representing no statistically significant change, base > test, and test > base. Consequently, we also undertake a non-spatial analysis of differences in proportions, comparing the actual percentage of areal units that have the same spatial point pattern test output (base > test for both alcohol outlets and assaults, for example), with a random assignment across the 3 possibilities, 33.33 percent.

\section{Results}

The counts and percentage change of alcohol outlets and crime (overall as well as for the six categories of crime) for both pre- and post-earthquake are presented in Table 1. Immediately obvious is a decrease in all cases from 2009 to 2014. The decrease in alcohol outlets is no surprise given the physical destruction that occurred in Christchurch, particularly in the central business district, a decrease of 100 alcohol outlets, just over 12 percent. All of the 
crime types decreased with theft decreasing the least at just under 4 percent. The decrease in all crime, just under 30 percent over 5 years, is a significant drop that may, in part, be a component of the international crime drop (Tseloni et al. 2010; Farrell et al. 2011). However, without a longer times series of data it is not possible to identify how much of this decrease, if any, is attributable to the international crime drop. As such, we concern ourselves with the changes in the spatial patterns, if any, for the variables under analysis. The other crime types all exhibit decreases in their counts, 2009 to 2014, ranging from 12 to 27 percent.

Table 1: Counts and percent change, alcohol outlets and crime types

\begin{tabular}{|l|l|l|l|}
\hline & 2009 & 2014 & Percent change \\
\hline Alcohol outlets & 805 & 704 & -12.54 \\
\hline All crime & 20134 & 17450 & -13.33 \\
\hline Assault & 2373 & 2095 & -11.72 \\
\hline Burglary & 5690 & 4389 & -22.87 \\
\hline Motor vehicle theft & 2022 & 1607 & -20.52 \\
\hline Robbery & 216 & 157 & -27.32 \\
\hline Social incivilities & 1603 & 1297 & -19.09 \\
\hline Theft & 8230 & 7905 & -3.95 \\
\hline
\end{tabular}

The difference in the count of all crime relative to the aggregate of the individual crime types analyzed here is based on a series of many crime codes used by the New Zealand police that do not have a high volume as well as police activities that do not directly relate to a crime or social incivilities, but other police activities such as drug-related calls and graffiti. In 2009, the seven individual crime types account for 55 percent of all crimes and, in 2014, the seven individual crime types account for 67 percent of all crimes. The seven individual crime types were chosen because of their volume in the crime data that allows for statistical analysis but also because of their prominence in criminological research. 
The results of the spatial point patterns test are presented in Table 2 (column one) and Figures 2-9. The $S$-Index value for alcohol outlets is 0.664 , indicating that there is a moderate degree of similarity in the spatial distribution of alcohol outlets pre- and post-earthquake, but enough change such that these two spatial patterns should not be considered similar. The $S$ Index values for the various crime types vary from 0.168 (all crime) to 0.546 (robbery), indicating that there is less similarity in the spatial patterns of crime pre- and post-earthquake. This may be because of changes in the spatial patterns of crime that are a result of the international crime drop—see Hodgkinson et al. (2016) for a discussion of this spatial shift in the context of motor vehicle theft.

Considering the mapped output of the spatial point pattern test, the central business district has definitely exhibited a decrease in the relative distribution of alcohol outlets (see Figure 2). Moreover, there has been a shift to the areas surrounding the central business district and a decrease in the relative distribution of alcohol outlets south of the central business district, consistent with the distribution of damaged buildings that occurred from the earthquakes during this time. The spatial point pattern test output for all crime is shown in Figure 3. Immediately apparent is that the spatial distribution of crime changed in a manner consistent with the earthquake damage: significant decreases in the distribution of all crime in and immediately around the central business district and just to the south of the business district. Assaults, burglary, social incivilities, and theft (see Figures 4, 5, 8, and 9) also exhibited decreases in the relative distribution of criminal events in and around the central business district, but the decreases are more dispersed across the city. Motor vehicle theft and robbery, Figures 6 and 7, have decreases that are much more tightly clustered in and around the central business district. Overall, the various crime types all exhibited decreases in their relative distributions in similar places where alcohol outlets decreased. This result indicates 
that there is at least a partial relationship between the decreased relative distribution of alcohol outlets and the decreased relative distribution of crime.

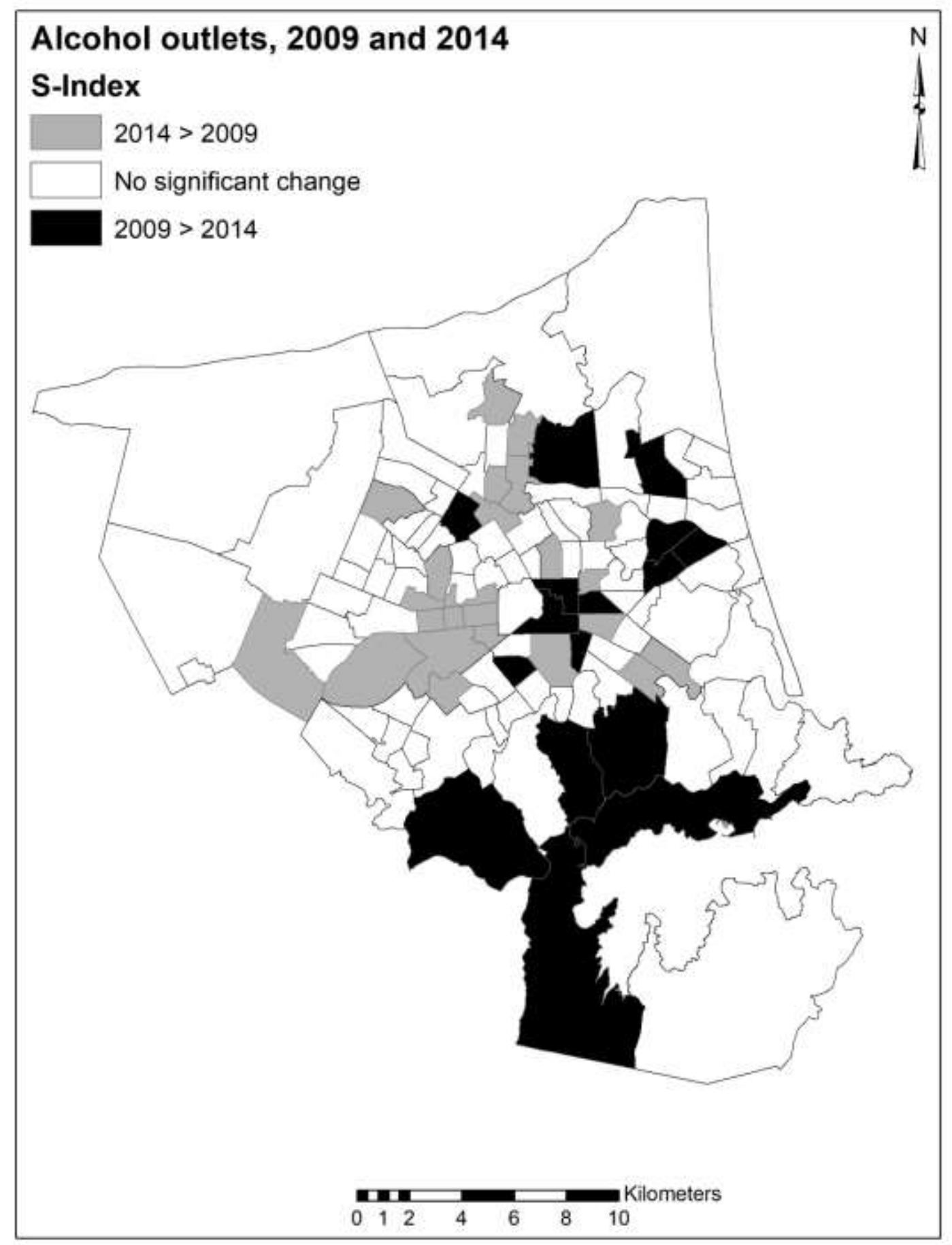

Figure 2: Spatial point pattern test output, 2009 to 2014, alcohol outlets 


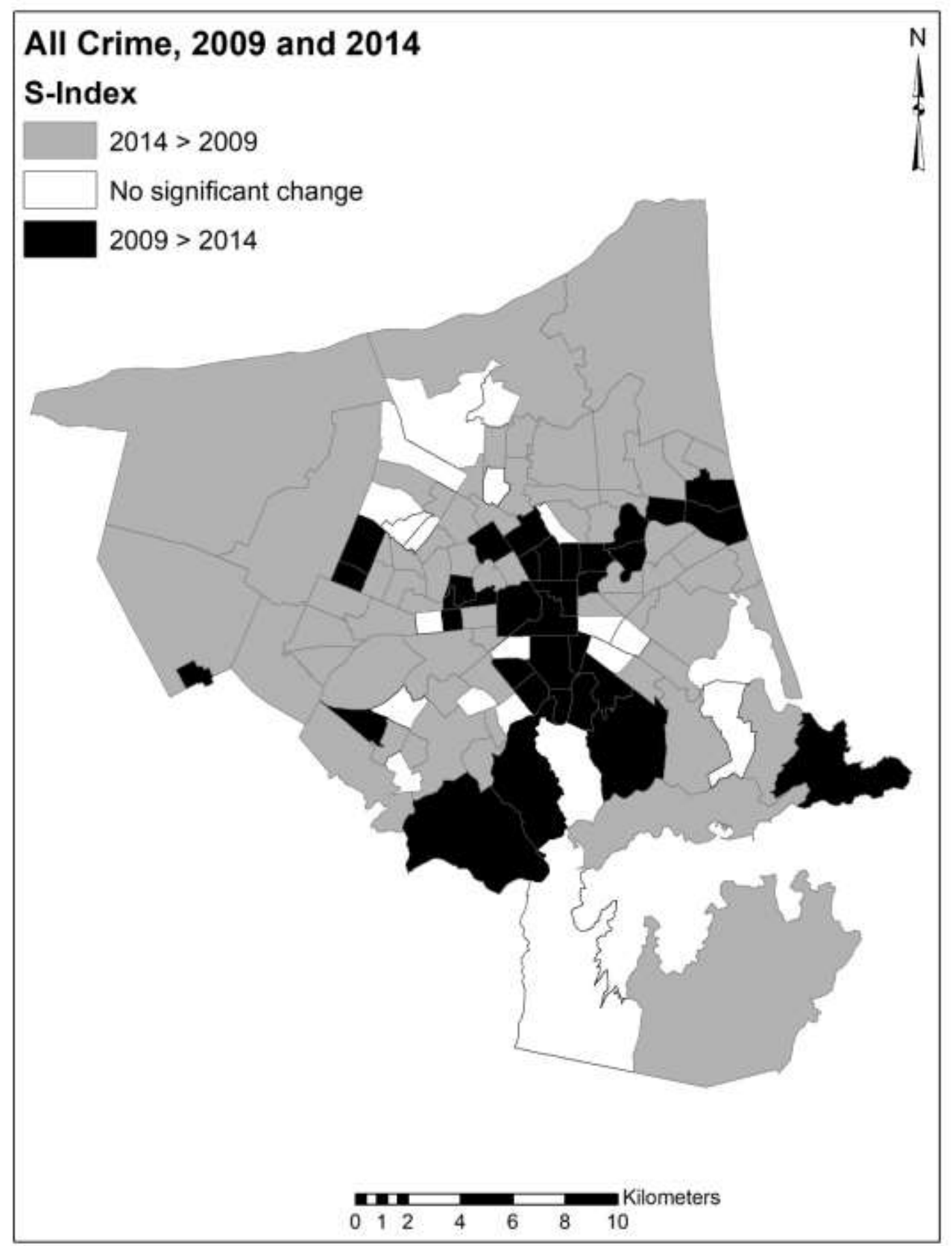

Figure 3: Spatial point pattern test output, 2009 to 2014, all crime 


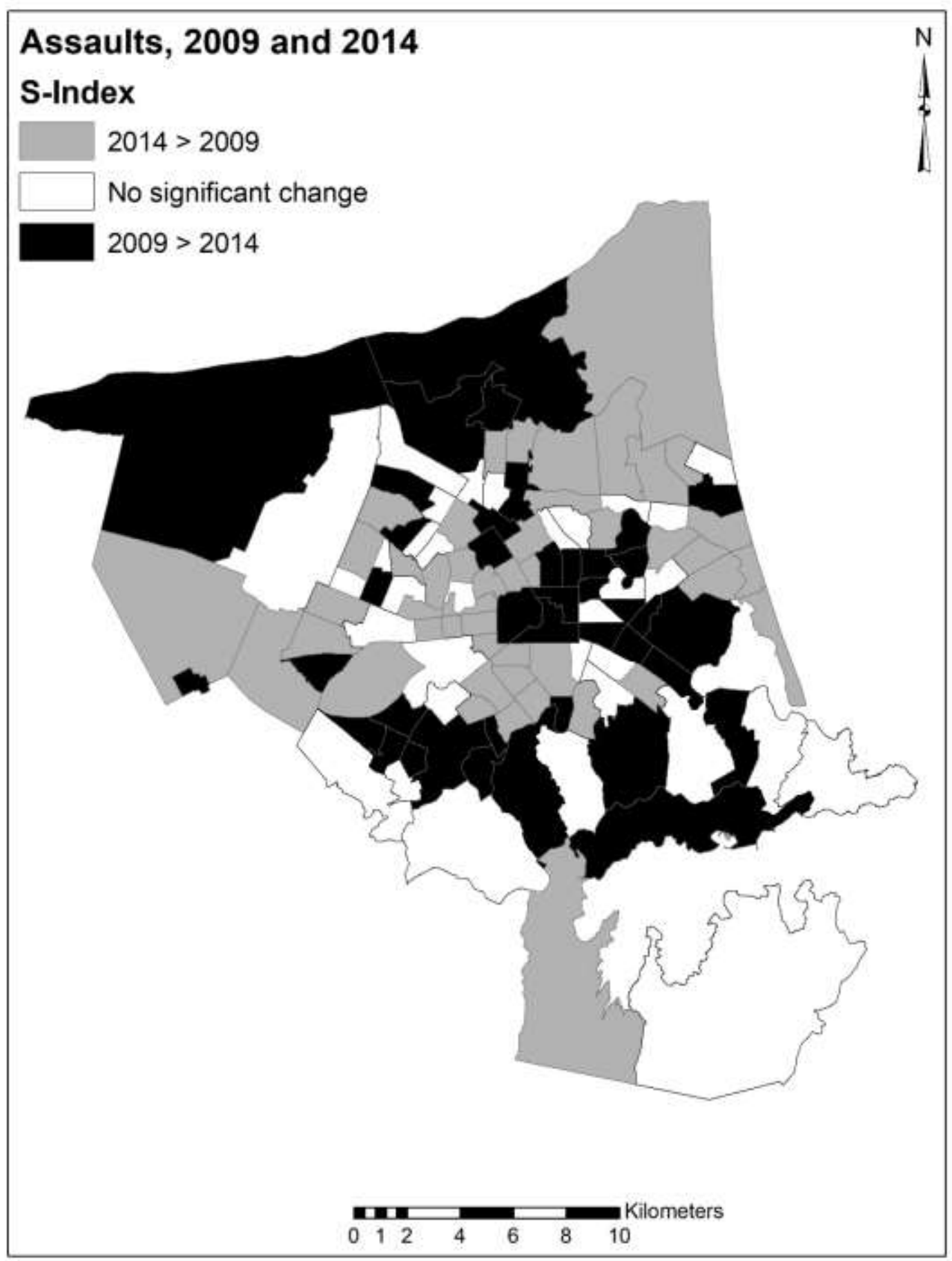

Figure 4: Spatial point pattern test output, 2009 to 2014, assault 


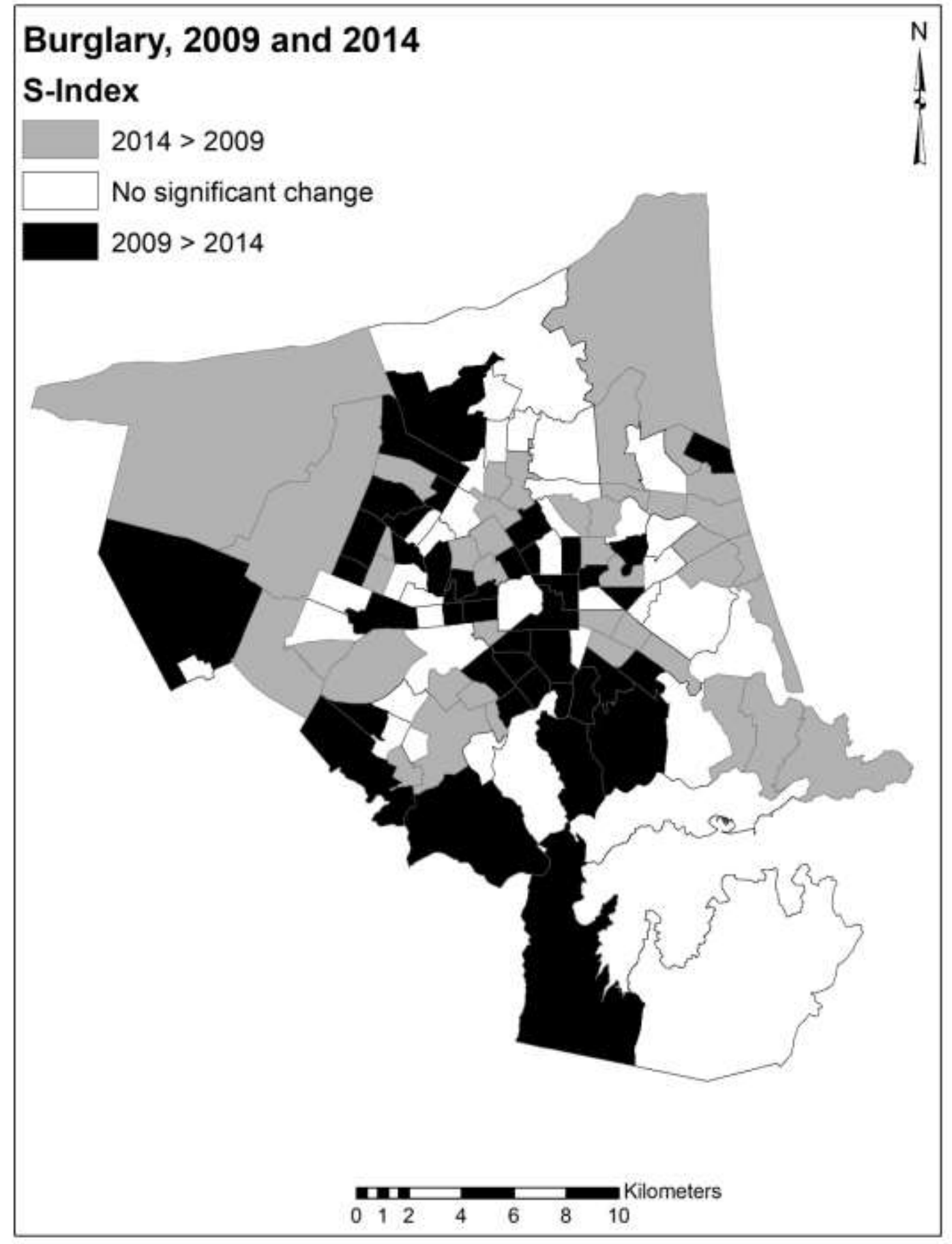

Figure 5: Spatial point pattern test output, 2009 to 2014, burglary 


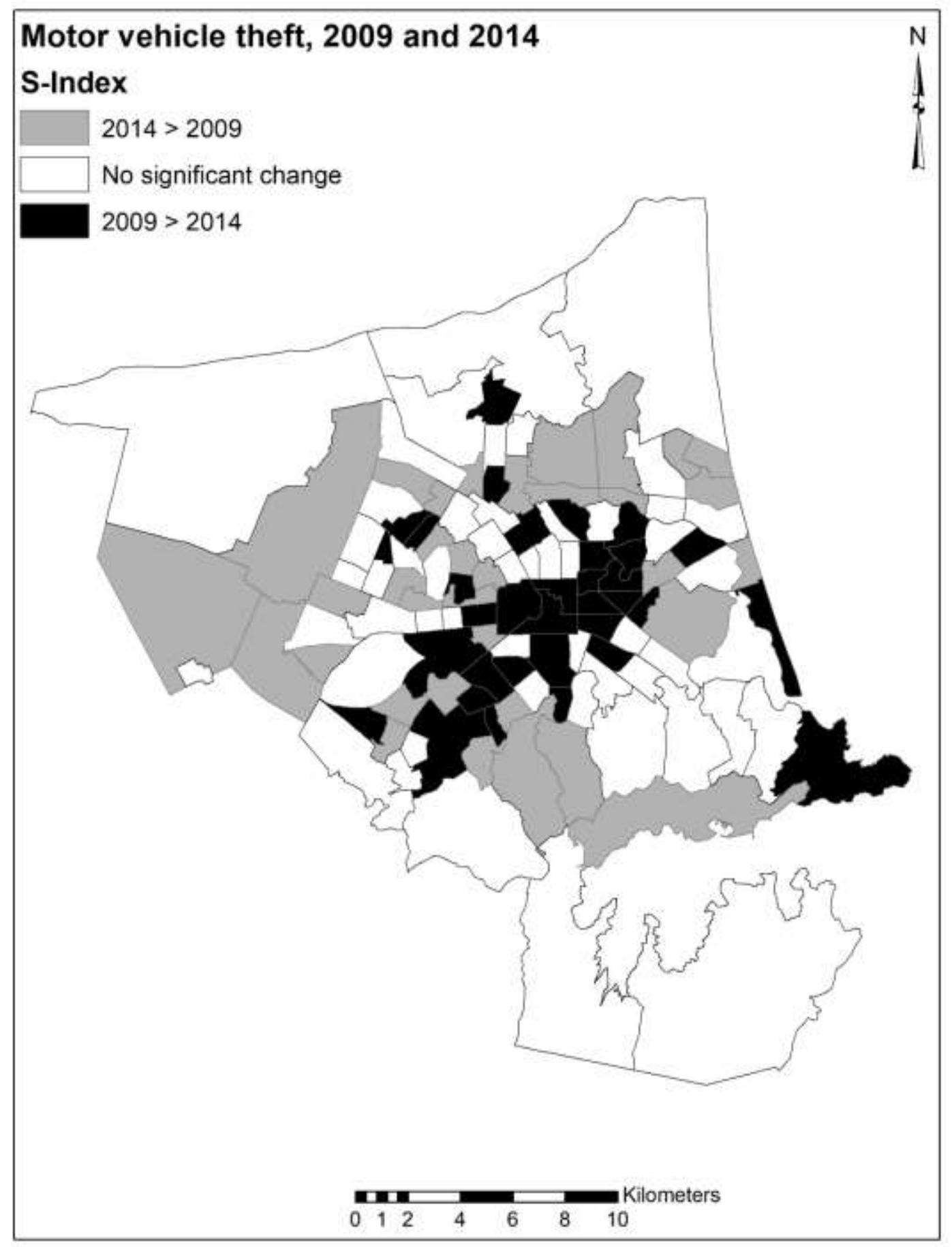

Figure 6: Spatial point pattern test output, 2009 to 2014, motor vehicle theft 


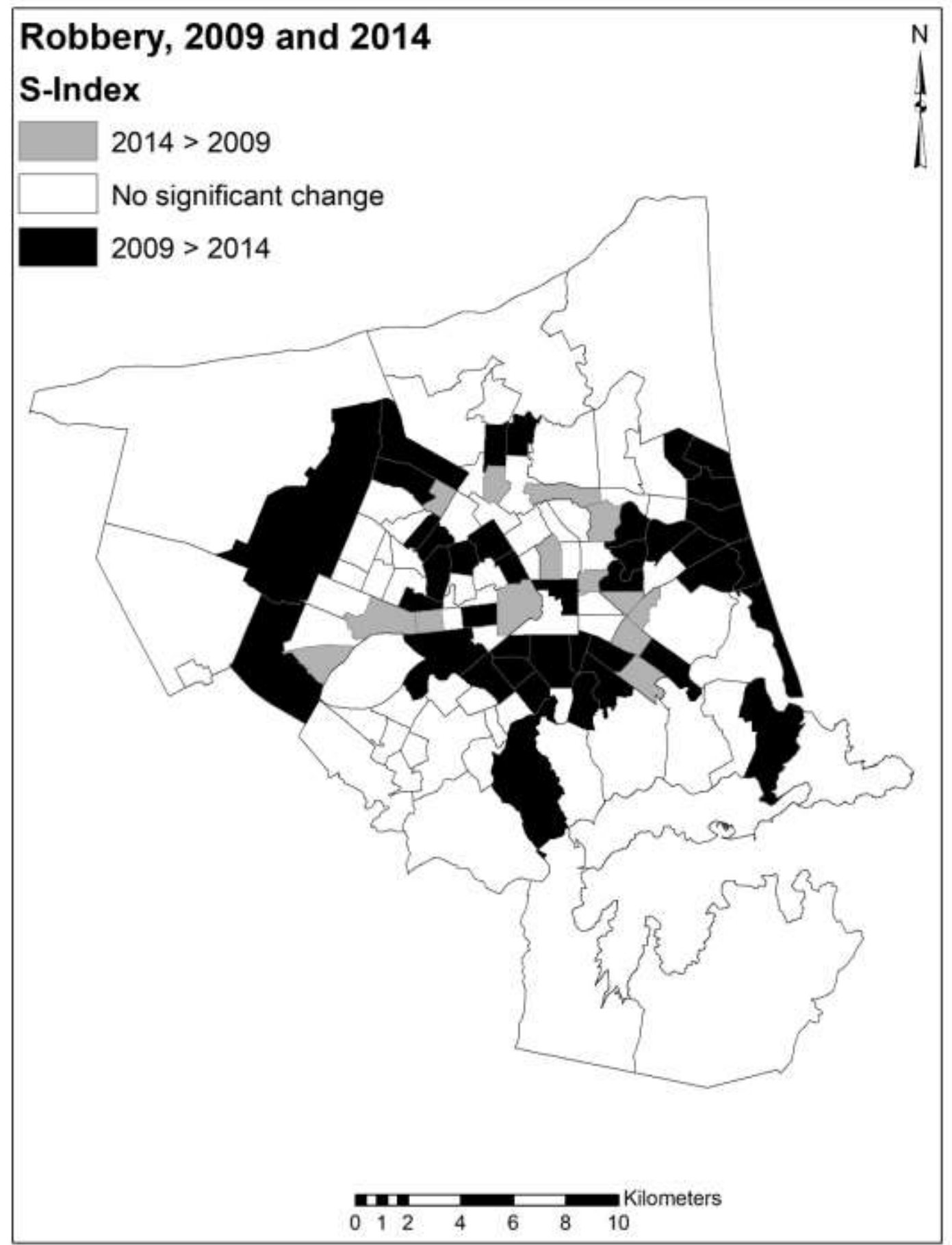

Figure 7: Spatial point pattern test output, 2009 to 2014, robbery 


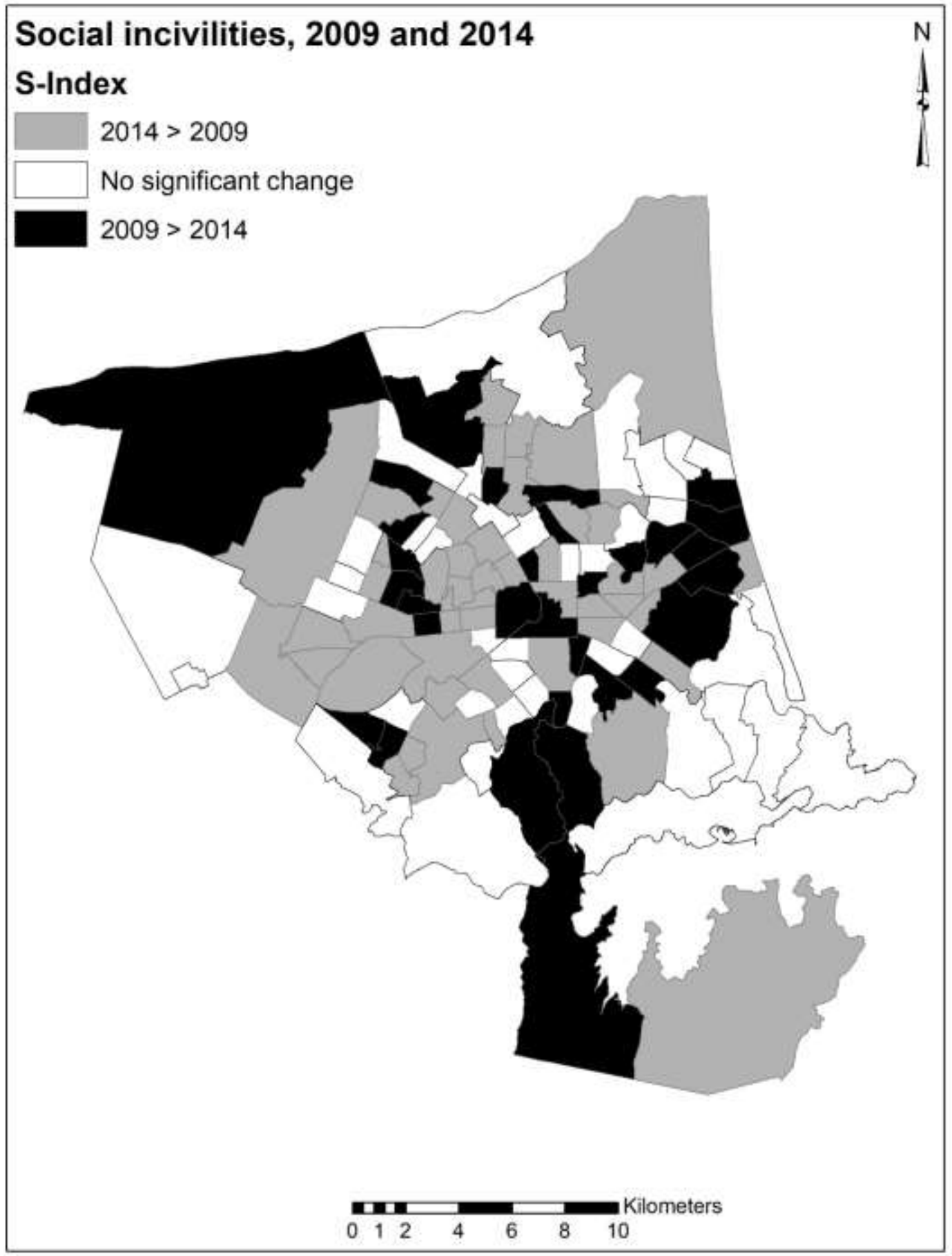

Figure 8: Spatial point pattern test output, 2009 to 2014, social incivilities 


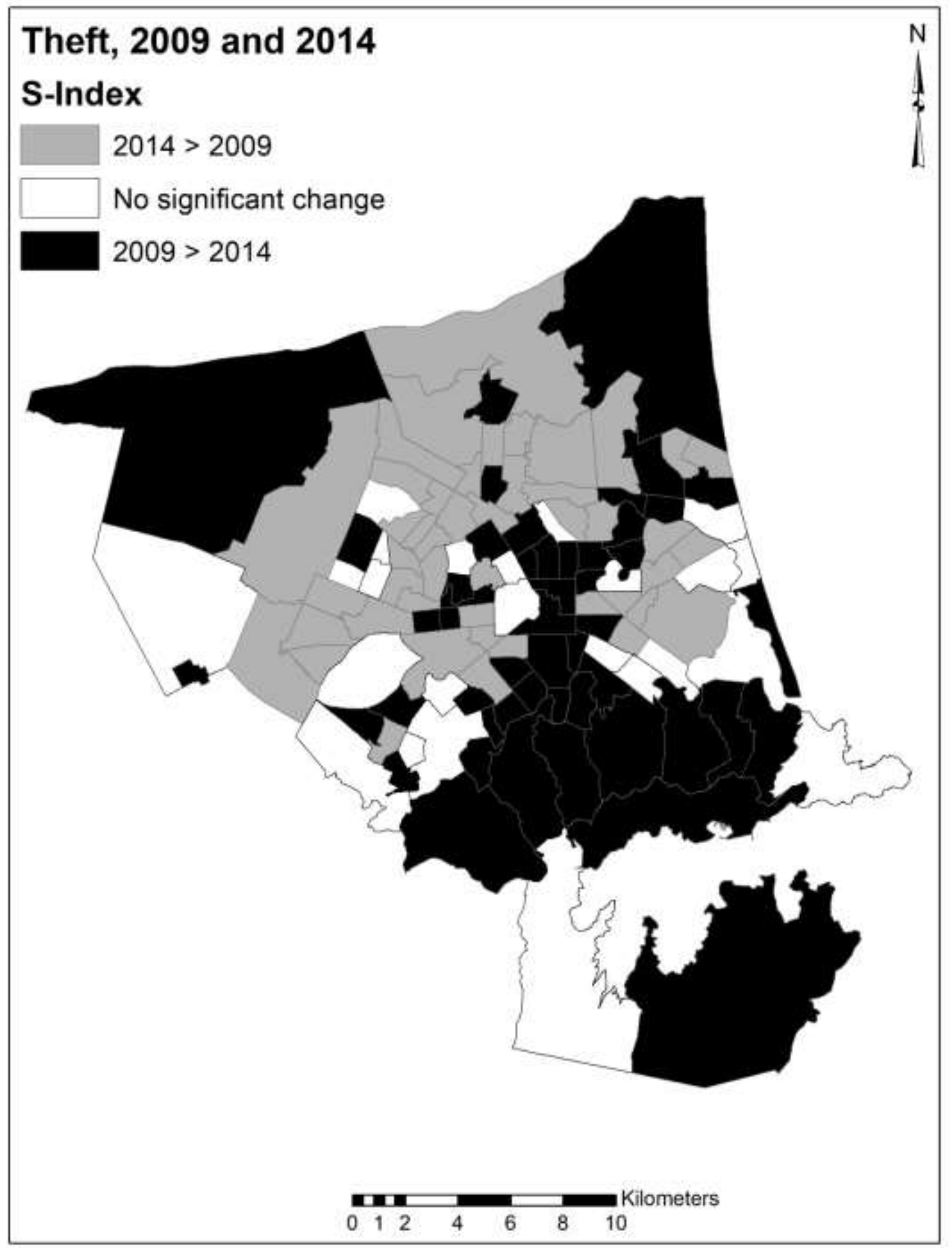

Figure 9: Spatial point pattern test output, 2009 to 2014, theft 
Table 2: Spatial point pattern test output, S-Indices, 2009 to 2014

\begin{tabular}{|l|l|l|l|}
\hline & S-Index & $\begin{array}{l}\text { Bivariate Moran's I with alcohol } \\
\text { outlets (p-value) }\end{array}$ & $\begin{array}{l}\text { Percent areal units, same } \\
\text { change }\end{array}$ \\
\hline Alcohol outlets & 0.664 & & \\
\hline All crime & 0.168 & $0.05(0.08)$ & 54.6 \\
\hline Assault & 0.277 & $0.04(0.15)$ & 68.9 \\
\hline Burglary & 0.303 & $-0.03(0.23)$ & 60.4 \\
\hline Motor vehicle theft & 0.429 & $-0.01(0.42)$ & 84.0 \\
\hline Robbery & 0.546 & $0.06(0.06)$ & 69.7 \\
\hline Social incivilities & 0.328 & $0.09(0.02)$ & 68.9 \\
\hline Theft & 0.193 & $0.14(<0.01)$ & \\
\hline
\end{tabular}

The bivariate Moran's I results, also shown in Table 2 (column 2) reveal that there is a positive statistical relationship between the changes in relative spatial distributions of alcohol outlets and the relative spatial distributions of crime types. Specifically, all crime, robbery, social incivilities, and theft all had positive bivariate Moran's $I$ values when compared with the alcohol outlets relative spatial distribution, albeit the statistical significance level for all crime and robbery is at the 10 percent level. However, it is important to note that the Moran's I values are relatively low magnitude and that because of the qualitative nature of the spatial point pattern test output, these results should be interpreted with caution.

The final set of analyses involved difference in proportions tests between the actual percentage of areal units that have the same spatial point pattern test output (base $>$ test for both alcohol outlets and assaults, for example), with a random assignment across the three possibilities, 33.33 percent. These results are shown in Table 2 (column 3). The percentage of areal units with the same classification in the spatial point pattern test, indicating similarity in pattern changes, ranges from 54.6 to 84.0 percent. All of these differences are statistically significant at the one percent level, so they are not reported in Table 2. This set of results 
shows that the changes, or no statistically significant changes, in the various crime types mirrored the changes, or lack thereof, in alcohol outlets to some extent. This similarity in the spatial point pattern test outputs, then, implies that there is a relationship between the changed relative spatial distribution of alcohol outlets and the changes in the relative spatial distributions of crime because the similarities in the percentages are far greater than would be expected by random chance.

\section{Discussion}

Consistent with the international crime drop literature, overall crime in the city has declined overall as well as across all six categories of crime examined in this study. In some instances, the decline is dramatic with robbery, for example, experiencing a $27 \%$ decline post-disaster although admittedly dropping from a low base. In terms of their spatial distribution, we found less similarity in the spatial patterning of crime pre- and post-earthquake than alcohol outlets suggesting that crime distributions changed more significantly. The fact that all the various crime types exhibited decreases in their relative distributions in similar places where alcohol outlets decreased provides a first empirical clue that there is at least a partial relationship between the decreased relative distribution of alcohol outlets and the decreased relative distribution of crime. Of course, the relationship between alcohol and crime is welldocumented with greater numbers of licensed outlets directly associated with greater rates of neighborhood-level crime and violence (Day et al. 2012; Lipton \& Gruenewald 2002). Whilst we have not shown a definitive link between alcohol and crime changing distributions here we have an indicated a possible association that warrants further investigation.

Of course, the fact that alcohol outlets and crime change in magnitude and spatial distribution following a natural disaster is, to some extent, understandable. Cities experiencing such disasters most often sustain significant damage particular to their built 
environment that can result in closures and/or relocations of existing alcohol outlets as well as changes in the opportunities for crime resulting in differing crime patterns; both of these phenomena are evidenced in this research. But what are the possible implications of these spatial changes? From a purely alcohol perspective it is likely that neighbourhoods experiencing an increase in outlets are also likely to experience in increase in alcohol-related harms (see Freisthler et al. 2004; Freisthler et al. 2005; Meliker et al. 2004). Classic 'availability theory' posits that the increased provision of alcohol in neighbourhoods results in increased consumption, heavy drinking and a wealth of alcohol-related health and social problems (Single 1988). Conversely, however, one would expect that a reduction in outlet density in neighbourhoods (such as the Christchurch CBD) should result in a concomitant decrease in associated alcohol-related harms. While these relationships are necessarily more variable and complex than we outline, and whilst our summation implies spatial determinism, the vast number of local and international studies that have found linkages between outlet density and a variety of alcohol-related problem suggest that changes in alcohol-related harms are likely in affected neighbourhoods in Christchurch.

From a crime perspective, the changing spatial patterning of crime found in this study reflects the changing opportunities for crime present in the city post-quake. We found that crime patterns changed significantly with a diffusion to areas outside the CBD. This knowledge presents two opportunities: first, there is an opportunity for New Zealand Police to integrate this 'new' knowledge into their existing tactical, operational and strategic plans for crime prevention in the city. For example, knowing where crime is more likely to occur post-quake can guide the location of vehicle and foot patrols and/or stop-and-frisk operations. Second, there is an opportunity for those institutions tasked with demolishing and rebuilding the city, and the central city in particular, to 'design out' crime. That is, to reduce 
opportunities for crime by incorporating Crime Prevention through Environmental Design (CPTED) principles in all rebuild projects.

The current rebuild process is governed by the Christchurch Central Recovery Plan (CCRP) that provides a spatial framework for the rebuilt city by setting out the locations of key urban anchor projects (Johnson \& Mamula-Seadon 2014). One key objective of the CCRP is to investigate ways to bring people, business and investment back to the central city. Prior to the earthquake almost $12 \%$ of all crime in Christchurch occurred in the central city and while crime has decreased by almost $70 \%$ in central city post-quake (Breetzke et al., in press) there is growing concern that these crime levels will return when the rebuild process is complete. After extensive lobbying by the Christchurch City Council there is now a formal requirement for CPTED to be considered for properties subject to resource consents in the central city business zone of the central city (Ramsey 2013). While this development is applaudable, and certainly necessary, there is an additional need to widen the uptake of CPTED across the city and create a positive and informed understanding within stakeholder groups and the community of the importance of this multi-disciplinary approach commonly used to reduce crime.

Specifically in the context of alcohol outlets and the importance of implementing CPTED principles, it is evident that the Canterbury Earthquakes had a significant effect on the number and spatial distribution of alcohol outlets and crime in Christchurch. As would be expected, given the physical destruction that the city experienced, the number of alcohol outlets decreased post-earthquake by over $12 \%$ with the majority of outlets located in the CBD closing down either temporarily or, in some instances, permanently. Indeed, only $24 \%$ of registered alcohol outlets that were open in the Christchurch CBD before the earthquake, returned to the CBD after the cordon was lifted and were open post-earthquake (end-2014). The remaining 226 alcohol outlets (76\%) either relocated permanently or closed down. Of the 
805 alcohol outlets operating in Christchurch before the earthquake only $56 \%(n=476)$ were operating by the end of 2014. The remaining 329 outlets closed down permanently. The number of outlets operating in Christchurch at the end of $2014(\mathrm{n}=705)$ reflects the 476 outlets that reopened as well as 229 new licenses, the vast majority of which opened in a new spatial location. From a purely geographic perspective, we found a moderate degree of spatial similarity in the distribution of alcohol outlets pre- and post-earthquake with a shift of outlets to areas surrounding the central business district and a decrease in the relative distribution of alcohol outlets south of the CBD. As such, any rebuilding or redevelopment of alcohol outlet districts need to consider CPTED early in the planning stages because of the known relationship between alcohol outlets and crime.

Though instructive, our analyses are not without limitations. First, we grouped all types of alcohol outlets together in this study and did not categorise by outlet type (i.e., on- or offpremise licenses). We are aware of the issues that arise when aggregating alcohol outlet data. These were recently highlighted by Gmel et al. (2016) whose particular concern is the fact that when studies aggregate different outlet types, a certain type of outlet (e.g., on-premise licenses) can explain most of the aggregated (e.g. total alcohol outlets) effect found in subsequent analyses. However, we agree with Morrison et al. (2016) who argue that while aggregation based studies may contain potential biases, a broad-brush aggregated and ecological approach to alcohol outlet studies still has merit. There are ten different types of alcohol licenses based on the ARLA criteria and disaggregating these data would be superfluous to the main aim of this research that was to examine how alcohol outlets (as a proxy for alcohol availability) changed in the aftermath of the Canterbury Earthquakes. Future research could certainly investigate how different types of alcohol outlet changed in the aftermath of the Canterbury Earthquakes, however that was not our main aim here. 
Second, one of the statistical methods was used with variables that are categorical, bivariate Moran's I. Our set of analyses included this method as only one component that was generally consistent with our other results, so we do not consider this limitation particularly problematic. And, finally, though unlikely based on our set of results, it is possible that the results presented here are spurious because we do not control for a set of other (demographics, economic, environmental, and social) variables that may be contributing to the changes in the relative spatial distributions of crime types; we consider this an avenue for future research.

The shortcomings of our analysis are complemented by its strengths. First, we found how the spatial stability of both alcohol outlets and crime across six different categories change in the aftermath of a natural disaster. We used a novel method to show how these spatial point patterns changed over the six-year study period. To our knowledge this is one of the first studies that specifically investigates the impact of a natural disaster on the spatial distribution of alcohol outlets in particular. Second, we explored the effect of a natural disaster on alcohol outlets and crime in a new context and geographic locale. Previous examination of the effects of natural disasters on related phenomena such as crime and health have been done almost exclusively in the United States and Asia. Finally, we highlight the potential consequences and opportunities that a new spatial reconfiguration of alcohol outlets and crime could present to relevant stakeholders, although future research could, and should, test the veracity of the implications and suggestions we outline. 


\section{References}

Adams PR, Adams GR (1984). Mount Saint Helens's ashfall. Evidence for a disaster stress reaction. The American Psychologist, 39 (3), 252-260.

Andresen MA (2009). Testing for similarity in area-based spatial patterns: A nonparametric Monte Carlo approach. Applied Geography 29 (3), 333-345.

Andresen MA (2010). Canada - United States interregional trade: Quasi-points and spatial change. Canadian Geographer 54 (2), 139-157.

Andresen MA (2016). An area-based nonparametric spatial point pattern test: the test, its applications, and the future. Methodological Innovations 9, Article 12.

Andresen MA, Linning SJ (2012). The (in)appropriateness of aggregating across crime types. Applied Geography 35 (1-2), 275 - 282.

Andresen MA, Malleson N (2013). Crime seasonality and its variations across space. Applied Geography 43, 25 - 35 .

Andresen MA, Malleson N (2013). Spatial heterogeneity in crime analysis. In: Leitner M, ed. Crime Modeling and Mapping using Geospatial Technologies. Springer, New York, NY, pp. 3-23. 
Andresen MA, Malleson N (2014). Police foot patrol and crime displacement: a local analysis. Journal of Contemporary Criminal Justice 30 (2), 186 - 199.

Anselin L (1995). Local indicators of spatial association - LISA. Geographical Analysis $27(2), 93-115$.

Ayuka F, Barnett R, Pearce J (2014). Neighbourhood availability of alcohol outlets and hazardous alcohol consumption in New Zealand, Health and Place 29 186-199.

Barsky L, Trainor J, Torres M (2006). Natural hazards center quick response report Number 184. February 2006. Natural Hazards Center, University of Colorado at Boulder.

Breetzke GD, King M, Fabris-Rotelli I (in press). The impact of the Canterbury Earthquakes on crime in Christchurch, New Zealand. Australian and New Zealand Journal of Criminology.

Burke Jr JD, Borus JF, Burns BJ, Millstein KH, Beasley MC (1982). Changes in children's behavior after a natural disaster. American Journal of Psychiatry 139 (8), 1010-1014.

Cameron MP, Cochrane W, McNeill K, Melbourne P, Morrison SL, Robertson N (2012). The impacts of liquor outlets in Manukau City summary report - revised. Alcohol Advisory Council of New Zealand, Wellington.

Cameron L, Shah M (2015). Risk-taking behavior in the wake of natural disasters. Journal of Human Resources 50 (2), 484-515. 
Cepeda A, Valdez A, Kaplan C, et al (2010). Patterns of substance use among Hurricane Katrina evacuees in Houston, Texas. Disasters 34 (2), 426-446.

Cerda M, Tracy M, Galea S (2011). A prospective population based study of changes in alcohol use and binge drinking after a mass traumatic event. Drug and Alcohol Dependence 115 (2011), 1-8.

Cohen DA, Ghosh-Dastidar B, Scribner R, Miu A, Scott M, Robinson P, Farley TA, Bluthenthal RN, Brown-Taylor D (2006). Alcohol outlets, gonorrhoea, and the Los Angeles civil unrest: a longitudinal analysis. Social Science \& Medicine 62 (12), 30623071.

Conrow L, Aldstadt J, Mendoza NS (2015). A spatio-temporal analysis of on-premises alcohol outlets and violent crime events in Buffalo, NY. Applied Geography 58, 198205.

Farrell G, Tseloni A, Mailley J, Tilley N (2011). The crime drop and the security hypothesis. Journal of Research in Crime and Delinquency 48 (2), 147 - 175.

Cromwell P, Dunham R, Akers R, Lanza-Kaduce L (1995). Routine activities and social control in the aftermath of a natural catastrophe. European Journal on Criminal Policy and Research 3 (3), 56-69.

Day P, Breetzke GD, Kingham S, Campbell M (2012). Close proximity to alcohol outlets is 
associated with increased serious violent crime in New Zealand. Australian and New Zealand Journal of Public Health 36 (1), 48-54.

Fothergill A (1996). Gender, risk, and disaster. International Journal of Mass Emergencies and Disasters 14 (1), 33-56.

Freisthler B, Midanik L, Gruenewald P (2004). Alcohol outlets and child physical abuse and neglect: applying routine activities theory to the study of child maltreatment. Journal of Studies of Alcohol and Drugs 65 (5), 586-92.

Freisthler B, Needell B, Gruenewald P (2005). Is the physical availability of alcohol and illicit drugs related to neighbourhood rates of child maltreatment? Child Abuse and Neglect 29 (9), 1049-1060.

Gatrell AC, Bailey TC, Diggle PJ, Rowlingson BS (1996). Spatial point pattern analysis and its application in geographical epidemiology. Transactions of the Institute of British Geographers 21 (1), $256-274$.

Getis A, Ord JK (1992). The analysis of spatial association by use of distance statistics. Geographical Analysis 24 (3), 189 - 206.

Gray J, Wilson E (1984). Looting in disasters: A general profile of victimization. Working Paper 71. Columbus, OH, The Ohio State University Disaster Research Center. 
Gmel G, Holmes J, Studer J (2016). Are alcohol outlet densities strongly associated with alcohol-related outcomes? A critical review of recent evidence. Drug and Alcohol Review 35, 40-54.

Harper DW, Frailing K (2012). Crime and Criminal Justice in Disaster. Carolina University Press, Durham, NC.

Gruenewald PJ, Remer L (2006). Changes in outlet densities affect violence rates. Alcoholism: Clinical and Experimental Research 30 (7), 1184-1193.

Hodgkinson T, Andresen MA, Farrell G (2016). The decline and locational shift of automotive theft: a local level analysis. Journal of Criminal Justice 44 (1), 49-57.

Johnson FW, Gruenewald PJ, Remer LG (2009). Suicide and alcohol: Do outlets play a role? Alcoholism: Clinical and Experimental Research 33 (12), 2124-2133.

Johnson LA, Mamula-Seadon L (2014). Transforming governance: How national policies and organizations for managing disaster recovery evolved following the 4 September 2010 and 22 February 2011 Canterbury Earthquakes. Earthquake Spectra 30 (1), 577- 605.

LeBeau JL (2002). The impact of a hurricane on routine activities and on calls for police service: Charlotte, North Carolina, and Hurricane Hugo. Crime Prevention and Community Safety: An International Journal 4, 53-64. 
Lee YY (2010). Gentrification and crime: Identification using the 1994 northridge earthquake in Los Angeles. Journal of Urban Affairs 32 (5), 549-577.

Leitner M, Helbich M (2011). The impact of hurricanes on crime: A spatio-temporal analysis in the city of Houston, Texas. Cartography and Geographic Information Science $\mathbf{3 8}$ (2), 213-221.

Leitner M, Barnett M, Kent J, Barnett T (2011). The impact of Hurricane Katrina on reported crimes in Louisiana: A spatial and temporal analysis. The Professional Geographer 63 (2), 244-261.

Linning SJ (2015). Crime seasonality and the micro-spatial patterns of property crime in Vancouver, BC and Ottawa, ON. Journal of Criminal Justice 4 (6), 544 - 555.

Lipton R, Gruenewald P (2002). Spatial dynamics of violence and alcohol outlets. Journal on Studies of Alcohol and Drugs 63 (2), 187-95.

Livingston M (2008). A longitudinal analysis of alcohol outlet density and assault. Alcoholism: Clinical and Experimental Research 32 (6), 1074-1079.

Mearidy-Bell L (2013). Adolescent victims of natural disasters: A phenomenological study of health on lived experiences and behaviors displayed after a crisis. Journal of Human 
Behavior in the Social Environment 23 (4), 536-551.

Meliker JR, Maio RF, Zimmerman MA, Kim HM, Smith SC, Wilson ML (2004). Spatial analysis of alcohol-related motor vehicle crash injuries in southeastern Michigan. Accident Analysis \& Prevention 36, 1129 - 1135.

Morrison C, Cerda M, Gorman DM, Gruenewald PJ, Mair CF, Naimi TS, Scribner R, Stockwell T, Toomey TL, Wieczorek WF (2016). Commentary on Gmel et al. (2015): are alcohol outlet densities strongly associated with alcohol-related outcomes? A critical review of recent evidence. Drug and Alcohol Review 35, 55-57.

Morrow BH (1997). Stretching the Bonds: The families of Andrew. In: Peacock WG, Morrow BH, Gladwin H, eds. Hurricane Andrew: Ethnicity, Gender and the Sociology of Disasters. Routledge, New York, pp. 141-170.

Prelog AJ (2016). Modeling the relationship between natural disasters and crime in the United States. Natural Hazards Review, 17 (1).

Ramsey S (2013). The role of CPTED in post-earthquake Christchurch. Safer Communities Journal - A Journal of Practice, Opinion, Policy and Research 12 (4).

Ratcliffe JH (2004). Geocoding crime and a first estimate of a minimum acceptable hit rate. International Journal of Geographical Information Science 18 (1), 61-72. 
Rohrbach LA, Grana R, Vernberg E, Sussman S, Sun P (2009). Impact of Hurricane Rita on adolescent substance abuse. Psychiatry 72 (3), 222-237.

Schroeder J, Polusny M (2004). Risk factors for adolescent alcohol use following a natural disaster. Prehospital and Disaster Medicine 19 (1), 122-127.

Scribner R, Theall KP, Ghosh-Dastidar B, Mason K, Cohen D, Simonsen, N (2007).

Determinants of social capital indicators at the neighbourhood level: a longitudinal analysis of loss of off-sale alcohol outlets and voting. Journal of Studies on Alcohol and Drugs 68 (6), 934-943.

Single EW (1988). The availability theory of alcohol-related problems. In: Chaudron CD, Wilkinson DA, eds. Theories on Alcoholism. Addiction Research Foundation, Toronto, pp. 325-351.

Tompson L, Johnson S, Ashby M, Perkins C, Edwards P (2015). UK open source crime data: Accuracy and possibilities for research. Cartography and Geographic Information Science 42 (2), 97-111.

Tseloni A, Mailley J, Farrell G, Tilley N (2010). Exploring the international decline in crime rates. European Journal of Criminology 7 (5), 375-394.

Ursano RJ, Fullerton CS, Benedek DM (2009). What is psychopathology after disasters? Considerations about the nature of the psychological and behavioral consequences of disasters. In: Galea S, Norris FH, eds. Mental Health and Disasters, Cambridge 
University Press, Cambridge, pp. 131-142.

Varano SP, Schafer JA, Cancino JM, Decker SH, Greene JR (2010). A tale of three cities:

Crime and displacement after Hurricane Katrina. Journal of Criminal Justice 38 (1), $42-50$.

Walker WC, Sim S, Keys-Mathews L (2012). The impact of Hurricane on spatial-temporal patterns of crime in Mobile, Alabama. Proceedings from GeoScience 2012, Columbus, Ohio.

Walker WC, Sim S, Keys-Mathews L (2014). Use of geographically weighted regression on ecology of crime, response to Hurricane in Miami, Florida. In: Elmes A, Roedl G, Conley J, eds. Forensic GIS: The Role of Geospatial Technologies for Investigating Crime and Providing Evidence. Springer, The Netherlands, pp. 245-262.

Watanabe K, Tamura M (1995). Victim's behavior in the great Hanshin Earthquake and disaster countermeasures of the police. Reports of the National Research Institute of Police Science 36 (2), 29-29.

Zahran S, Shelley TO, Peek L, Brody SD (2009). Natural disasters and social order: 
Modeling crime outcomes in Florida. International Journal of Mass Emergencies and Disasters 27 (1), 26-52.

Zhou D (1997). Disaster, Disorganization, and Crime. University of Albany, State University of New York.

Zhang X, Hatcher B, Clarkson L, Holt J, Bagchi S, Kanny D, Brewer RD (2015). Changes in density of on-premises alcohol outlets and impact on violent crime, Atlanta, Georgia, 1997-2007. Preventing Chronic Disease 12, 1-10. 